\title{
Development and validation of a duplex real-time PCR assay for the diagnosis of equine piroplasmosis
}

\author{
Vladislav A. Lobanov ${ }^{1 *}$, Maristela Peckle², Carlos L. Massard² ${ }^{2}$ W. Brad Scandrett ${ }^{1}$ and Alvin A. Gajadhar ${ }^{1}$
}

\begin{abstract}
Background: Equine piroplasmosis (EP) is an economically significant infection of horses and other equine species caused by the tick-borne protozoa Theileria equi and Babesia caballi. The long-term carrier state in infected animals makes importation of such subclinical cases a major risk factor for the introduction of EP into non-enzootic areas. Regulatory testing for EP relies on screening of equines by serological methods. The definitive diagnosis of EP infection in individual animals will benefit from the availability of sensitive direct detection methods, for example, when used as confirmatory assays for non-negative serological test results. The objectives of this study were to develop a real-time quantitative polymerase chain reaction (qPCR) assay for simultaneous detection of both agents of EP, perform comprehensive evaluation of its performance and assess the assay's utility for regulatory testing.

Results: We developed a duplex qPCR targeting the ema-1 gene of T. equi and the 185 rRNA gene of B. caballi and demonstrated that the assay has high analytical sensitivities for both piroplasm species. Validation of the duplex qPCR on samples from 362 competitive enzyme-linked immunosorbent assay (CELISA)-negative horses from Canada and the United States yielded no false-positive reactions. The assay's performance was further evaluated using samples collected from 430 horses of unknown EP status from a highly endemic area in Brazil. This set of samples was also tested by a single-target 185 rRNA qPCR for T. equi developed at the OIE reference laboratory for EP in Japan, and a previously published single-target $18 \mathrm{~S}$ rRNA qPCR for B. caballi whose oligonucleotides we adopted for use in the duplex qPCR. Matching serum samples were tested for antibodies to these parasites using CELISA. By the duplex qPCR, T. equi-specific 18S rRNA qPCR and cELISA, infections with T. equi were detected in 87.9\% (95\% confidence interval, Cl: 84.5-90.7\%), 90.5\% (95\% Cl: 87.3-92.3\%) and 87. $4 \%$ (95\% Cl: 84.0-90.2\%) of the horses, respectively. The B. caballi prevalence estimates were 9.3\% (95\% Cl: 6.9-12.4\%) by the duplex QPCR and 7.9\% (95\% Cl: 5.7-10.9\%) by the respective single-target qPCR assay. These values were markedly lower compared to the seroprevalence of 58.6\% (95\% Cl: 53.9-63.2\%) obtained by B. caballi-specific cELISA. The relative diagnostic sensitivity of the duplex qPCR for T. equi was $95.5 \%$, as 359 of the 376 horses with exposure to T. equi confirmed by cELISA had parasitemia levels above the detection limit of the molecular assay. In contrast, only 39 (15.5\%) of the 252 horses with detectable B. caballi-specific antibodies were positive for this piroplasm species by the duplex qPCR. (Continued on next page)
\end{abstract}

\footnotetext{
*Correspondence: Vladislav.Lobanov@inspection.gc.ca

${ }^{1}$ Centre for Food-borne and Animal Parasitology, Canadian Food Inspection

Agency, Saskatoon, Saskatchewan, Canada

Full list of author information is available at the end of the article
} 
(Continued from previous page)

Conclusions: The duplex qPCR described here performed comparably to the existing single-target qPCR assays for T. equi and B. caballi and will be more cost-effective in terms of results turnaround time and reagent costs when both pathogens are being targeted for disease control and epidemiological investigations. These validation data also support the reliability of the ema-1 gene-specific oligonucleotides developed in this study for confirmatory testing of non-negative serological test results for $T$. equi by qPCR. However, the $B$. caballi-specific qPCR cannot be similarly recommended as a confirmatory assay for routine regulatory testing due to the low level of agreement with serological test results demonstrated in this study. Further studies are needed to determine the transmission risk posed by PCR-negative equines with detectable antibodies to B. caballi.

Keywords: Equine piroplasmosis, Theileria equi, Babesia caballi, Real-time PCR, Confirmatory assay

\section{Background}

Equine piroplasmosis (EP) is a haemoprotozoan infection of horses and other members of the family Equidae caused by two intracellular apicomplexan parasites, Theileria equi [1] and Babesia caballi [2]. Infections with either or both of these parasites may cause severe acute disease characterized by fever, hemolytic anemia, hemoglobinuria, icterus, splenomegaly and occasionally death. Animals that recover from a primary infection remain chronically infected and become inapparent carriers with fluctuating levels of parasitemia. The carrier state in equines infected with $T$. equi lasts a lifetime. Infections with B. caballi may persist for years; however, there is a contention that infected equines are capable of clearing B. caballi without babesiacidal treatment. Persistently infected carriers serve as a reservoir for iatrogenic and biological transmission of these parasites $[3,4]$. There is also evidence of transplacental transmission of $T$. equi from infected carrier mares to their fetuses that may lead to abortion, stillbirth or neonatal piroplasmosis $[3,5]$. Vector-borne transmission of EP is mediated by ixodid tick species belonging to the genera Dermacentor, Hyalomma and Rhipicephalus [6]. However, a member of the genus Amblyomma has also been shown to be a competent intrastadial vector of $T$. equi associated with a recent incursion of this pathogen in the USA $[7,8]$.

Importation of carrier animals with no overt signs of disease is a major risk factor for the introduction of EP into non-enzootic areas. Countries that wish to achieve or maintain EP-free status must enact regulations to restrict the entrance of infected equines. Therefore, EP presents a significant impediment to international movement of horses for trade and for participation in international equestrian events [6,9]. Sensitive and specific laboratory diagnostic methods are essential for revealing asymptomatic equines carrying these parasites. Blood smear microscopy provides a means of identifying the organisms during the acute stage of infection, but parasitemia levels are generally too low in the persistent stage of infection for reliable detection by this method $[10,11]$. Definitive diagnosis of EP is usually accomplished using one or a combination of the following serological methods: indirect immunofluorescent antibody test
(IFAT), cELISA and immunoblot assay. There is evidence of significantly higher sensitivity of IFAT compared to cELISA in detecting early infections with $T$. equi [12]. The complement fixation test (CFT) has high specificity, but lacks sensitivity in the chronic stage of infection $[13,14]$.

The cELISA utilizing the recombinant equi merozoite antigen 1 (EMA-1) protein of T. equi and a monoclonal antibody specific to this immunodominant surface protein is currently considered to be one of the most robust and sensitive methods for detecting antibodies to this organism in chronically infected animals $[13,15]$. The assay has been validated using a number of different geographical isolates of $T$. equi $[13,16]$. The currently available cELISA for $B$. caballi is based on specific inhibition of binding of a monoclonal antibody to the recombinant rhoptry-associated protein 1 (RAP-1) antigen of this parasite by serum antibodies of infected equines [17]. Although this assay generally has a higher diagnostic sensitivity than that of the CFT [17], it was unable to detect infections with certain geographical isolates of $B$. caballi due presumably to sequence heterogeneity in the rap-1 gene and its product $[18,19]$. The validity of the RAP-1 cELISA for use as a singular diagnostic test for $B$. caballi has thus been questioned $[18,20]$.

Recent advances in molecular diagnostics have led to the development of an array of sensitive detection methods for EP based on targeted amplification of specific genomic loci of T. equi and B. caballi. Among these methods are conventional PCR [10, 21, 22], 'nested' PCR (nPCR) [11, 23, 24], PCR followed by detection of amplicons by reverse line blotting with non-radioactive probes [25], loop-mediated isothermal amplification [26] and qPCR [27-30]. The highest analytical sensitivity values were reported for $\mathrm{nPCR}$ and qPCR methods. Thus, nPCR targeting the ema-1 gene of $T$. equi has been shown to produce a positive result at a parasitemia level of $6 \times 10^{-6} \%$ infected cells [11], whereas DNA of $B$. caballi was detected by a rap- 1 gene-specific $\mathrm{nPCR}$ in all serial dilutions of infected equine erythrocytes down to a single parasitized cell [24]. In addition to also being very sensitive, the advantages of qPCR over nPCR and other currently available PCR-based methods include speed, ease of 
performance, quantitative ability and a lower risk of carryover contamination due to the absence of a need for postamplification manipulation of the products [31]. Genomic sites targeted by described qPCR assays for EP include the $18 S$ rRNA gene of T. equi [30] and its homolog in B. caballi [27], as well as genes encoding immunodominant surface proteins of these parasites, such as the ema-1 gene of T. equi $[28,32]$ and the $48 \mathrm{kDa}$ merozoite rhoptry protein (bc48) gene of $B$. caballi [29]. There is evidence suggesting that the translation products of $b c 48$ and rap-1 genes represent the same protein [17]. A duplex real-time PCR for simultaneous detection of both $T$. equi and $B$. caballi has also been described [29]. This assay utilized ema-1 gene-specific primers and probe that were adopted from earlier studies where these oligonucleotides were used for the quantification of parasitemia levels of $T$. equi in experimentally infected animals by single-target qPCR $[32,33]$. However, a suboptimal diagnostic sensitivity for that single-target qPCR assay was later reported when it was used to test field samples in South Africa [28], due to the ema-1 gene sequence heterogeneity in a subset of isolates originating from that geographical region.

Effective protocols for chemotherapeutic clearance of persistent infections using a carbanilide derivative, imidocarb dipropionate, have been developed for both $T$. equi and $B$. caballi $[12,34,35]$. Serial negative PCR test results will likely remain one of the requirements for verifying successful parasite elimination post-treatment, broadening the applicability of well-validated PCR assays for the regulatory control of EP.

The objectives of this study were to adopt the already well-characterized $18 S$ rRNA gene-specific oligonucleotides for B. caballi developed by Bhoora et al. [27] and develop new compatible T. equi-specific primers and hydrolysis probe for incorporation into a new duplex qPCR assay, determine analytical sensitivities of this assay for both piroplasm species, and compare diagnostic performance of the duplex qPCR against that of the cELISA and selected single-target qPCR assays using known negative (diagnostic specificity) and unknown status field samples from an enzootic area (relative diagnostic sensitivity).

\section{Methods}

Field samples

Samples from horses located in non-enzootic areas for EP

( $n=362)$

Matching samples of serum and whole EDTA blood were obtained from an abattoir located in Canada in April 2012 from 30 Canadian horses and 30 horses imported from the USA. Additional archived cryopreserved matching samples of whole EDTA blood and serum collected from 302 horses and ponies in the USA during the period from 1987 to 2009 were obtained from the Gluck Equine Research Center (University of Kentucky, Lexington, KY, USA).

\section{Samples from horses located in an enzootic area for EP ( $n=430)$}

Matching samples of serum and EDTA blood were collected from 430 horses of unknown EP status (i.e. these animals had no apparent clinical symptoms of EP) residing in the state of Rio de Janeiro, Brazil in October 2013 to January 2014. All samples of whole blood and serum were stored until use at $-80{ }^{\circ} \mathrm{C}$ and $-20^{\circ} \mathrm{C}$, respectively.

\section{Optimization of the DNA extraction procedure}

Total DNA was extracted from $200 \mu$ of whole EDTA blood using the DNeasy Blood and Tissue Kit (Qiagen, Hilden, Germany). The manufacturer's protocol was preliminarily evaluated for its efficacy in removing PCR inhibitors present in blood from DNA preparations. To that end, DNA was extracted on two occasions from a stabilate of blood from a T. equi-infected horse obtained from the National Veterinary Services Laboratories, United States Department of Agriculture (NVSL/USDA; Ames, IA, USA). The extractions were performed either in strict accordance with the manufacturer's protocol, or with modifications that entailed two consecutive washes of the spin column containing DNA adsorbed to the filter with either Buffer AW1 or Buffer AW2, or the lysis of erythrocytes using RBC Lysis Solution (Qiagen, Germantown, MD, USA) followed by centrifugation and decanting of most of the supernatant containing PCR inhibitors released from the cells prior to the column purification. These DNA preparations were then analysed by duplex qPCR as described below, except that the amplifications were performed using the TaqMan Universal Master Mix II (Life Technologies, Warrington, UK) either with or without addition of $200 \mathrm{ng} / \mu \mathrm{l}$ of bovine serum albumin (BSA; non-acetylated $20 \mathrm{mg} / \mathrm{ml}$ solution in water; SigmaAldrich, St. Louis, MO, USA). Modifications that produced markedly reduced and more consistent quantification cycle (Cq) values in the duplex qPCR were incorporated into the final protocol.

The final modified DNA extraction procedure was as follows. Blood samples were transferred into tubes pre-filled with $600 \mu \mathrm{l}$ of RBC Lysis Solution (Qiagen) and mixed by inverting each tube a few times. This was followed by $5 \mathrm{~min}$ incubation at room temperature, a brief vortexing, and continued incubation for $5 \mathrm{~min}$. After a brief vortexing, the tubes were centrifuged at $17,000 \times g$ for $30 \mathrm{~min}$ at $4{ }^{\circ} \mathrm{C}$, and then most of the supernatant was discarded without disturbing the pellet. The remaining volume was adjusted to approximately $200 \mu \mathrm{l}$ with nucleasefree water (Life Technologies, Grand Island, NY, USA). The pellet was thoroughly re-suspended and processed according to the kit's protocol, except that two consecutive washes of the spin column with Buffer AW1 were performed. 


\section{Development of the duplex real-time PCR}

Twenty-two nucleotide sequences of the ema-1 gene of T. equi, namely L13784, AB015208-AB015220, AB015235, AB043618, AF255730, AF261824, AY058899, DQ250541, U97167 and U97168, were retrieved from GenBank and aligned using BioEdit 7.0.9 [36]. Primers and a minor groove binder (MGB) hydrolysis probe were designed using the AlleleID 7.72 software (Premier Biosoft, Palo Alto, CA, USA). The software parameters were set to avoid cross-homology with the equine genome and cross-hybridization interference with the adopted oligonucleotides specific to the $18 S$ rRNA gene of $B$. caballi [27]. The PCR product amplified in the duplex qPCR using the ema-1 gene-specific primers represents a 98 base pair fragment containing 89 nucleotides of the 3 ' extremity of this gene. Primers used in this study were synthesized by Integrated DNA Technologies (Coralville, IA, USA), whereas TaqMan MGB probes were obtained from Life Technologies (Carlsbad, CA, USA) (Table 1).

Real-time qPCR reactions were performed in a CFX96 Real-Time PCR Detection System (Bio-Rad, Hercules, CA, USA). Each $25 \mu \mathrm{l}$ duplex qPCR reaction contained $400 \mathrm{nM}$ of each TeEMA1-F and TeEMA1-R primer, 480 nM of each Bc_18SF402 and Bc_18SR496 primer, 200 nM of each TeEMA1-P and Bc_18SP probe and $2 \mu \mathrm{l}$ of DNA preparation in 1× TaqMan Environmental Master Mix 2.0 (Life Technologies). Supplementing the duplex qPCR reaction mixture with BSA was unnecessary, as the fully optimized assay was performed using a TaqMan PCR master mix with proprietary formulation designed to reduce the effect of common PCR inhibitors. The optimized cycling protocol consisted of the initial activation cycle at $95{ }^{\circ} \mathrm{C}$ for $10 \mathrm{~min}$, followed by 45 cycles of $30 \mathrm{~s}$ at $95{ }^{\circ} \mathrm{C}, 30 \mathrm{~s}$ at $57{ }^{\circ} \mathrm{C}$ and $20 \mathrm{~s}$ at $72{ }^{\circ} \mathrm{C}$ with fluorescence data acquisition after the elongation step. Negative controls consisting of nuclease-free water and DNA extracted from blood of an EP-free horse (Western

Table 1 Nucleotide sequences of primers and TaqMan MGB probes used in the duplex qPCR assay

\begin{tabular}{|c|c|c|}
\hline $\begin{array}{l}\text { Oligonucleotide } \\
\text { name }\end{array}$ & $\begin{array}{l}\text { Nucleotide sequence } \\
\left(5^{\prime}-3^{\prime}\right) \text { and modifications }\end{array}$ & Reference \\
\hline TeEMA1-F & CTGACTACAAGGTYGTATAC & This study \\
\hline TeEMA1-R & TGTCGTCACTTAGTAAAATAGA & This study \\
\hline TeEMA1-P & $\begin{array}{l}\text { 6-FAM-TTCTCCGTCTATGGCGCA-MGB- } \\
\text { NFQ }\end{array}$ & This study \\
\hline BC_18SF402 & GTAATTGGAATGATGGCGACTTAA & $\begin{array}{l}\text { Bhoora et al. } \\
{[27]}\end{array}$ \\
\hline BC_18SR496 & CGCTATTGGAGCTGGAATTACC & $\begin{array}{l}\text { Bhoora et al. } \\
{[27]}\end{array}$ \\
\hline BC_18SP & VIC-CCTCGCCAGAGTAA-MGB-NFQ & $\begin{array}{l}\text { Bhoora et al. } \\
{[27]}\end{array}$ \\
\hline
\end{tabular}

Abbreviations: $\mathrm{Y}, \mathrm{T}$ or $\mathrm{C} ; \mathrm{MGB}$, minor groove binder; $N F Q$,

non-fluorescent quencher
College of Veterinary Medicine (WCVM), University of Saskatchewan, Saskatoon, Canada) were included on each plate. Preparations of DNA extracted from stabilates of blood from horses infected with either T. equi or B. caballi (NVSL/USDA) were used as positive controls. Test samples with Cq values lower than 40 were considered positive.

To produce a plasmid containing the full-length ema-1 gene of T. equi, DNA extracted from a stabilate of blood infected with a Peru strain of T. equi (NVSL/USDA) was amplified by PCR using primers (TeEMA1-Start) 5'-ATG ATT TCC AAA TCC TTT GC-3' and TeEMA1-R (Table 1). The amplification product was cloned into the pCR4-TOPO vector (Life Technologies), and the resulting plasmid was named pCR4-ema-1. The accuracy of cloning was confirmed by Sanger nucleotide sequencing that was performed at the National Research Council, Plant Biotechnology Institute (Saskatoon, Canada).

\section{Evaluation of the duplex real-time PCR performance}

Amplification efficiency (E) values were calculated by the CFX Manager software (Bio-Rad) from slopes of standard curves produced by amplification of serially diluted templates (standards) according to the equation $\mathrm{E}$ $=\left(10^{-(1 / \text { Slope })}-1\right) \times 100 \%$. The linearity of data $\left(R^{2}>\right.$ $0.98)$, an $E$ value within the range of $90-110 \%$ and consistency of $\mathrm{Cq}$ values across replicates were considered indicative of a well-optimized qPCR.

A fresh sample of $T$. equi-infected equine blood suitable for determining the level of parasitemia by microscopy was not available for this study. Therefore, the analytical sensitivity of the duplex qPCR assay for detecting T. equi was evaluated using standards consisting of ten-fold serial dilutions of the plasmid pCR4-ema-1 linearized with the restriction enzyme Scal. The digestion product was purified from agarose gel using the QIAquick Gel Extraction kit (Qiagen) and its DNA concentration was measured using the NanoDrop 2000c spectrophotometer (Thermo Scientific, Wilmington, DE, USA). Dilutions of the fragment with specified numbers of ema-1 copies were prepared according to guidelines provided in the Applied Biosystems tutorial [37]. Four replicates of each dilution of these standards were amplified in the presence or absence of background DNA represented by $250 \mathrm{ng}$ per reaction of DNA from blood of an EP-free horse.

To determine the analytical sensitivity of the duplex qPCR for B. caballi, duplicate ten-fold serial dilutions of a sample of equine blood with $0.4 \%$ parasitemia (NVSL/ USDA) were prepared in uninfected equine blood. The level of parasitemia was determined by microscopy performed at 1,000× magnification on thin blood smears stained using a Diff-Quik Stain Set (Newark, DE, USA), and counting the proportion of infected erythrocytes in 
half of each of five fields of view. Total DNA was extracted from these dilutions according to the protocol described above. In addition, DNA extracted from an undiluted sample of this infected blood was used to prepare ten-fold serial dilutions in TE buffer $(10 \mathrm{mM}$ Tris- $\mathrm{HCl} \mathrm{pH}$ 8.0, $1 \mathrm{mM}$ EDTA). These two differently prepared sets of standards were amplified in quadruplicate by the duplex qPCR.

The diagnostic specificity of the duplex qPCR assay was evaluated by testing matching samples of whole blood and serum from the negative horse population by this molecular assay and cELISA, respectively. The relative diagnostic sensitivity and specificity of the duplex qPCR were assessed using samples collected from 430 horses of unknown infection status from an enzootic area for EP in Brazil. The sera were tested for antibodies to both $T$. equi and B. caballi by cELISA. The samples of whole blood were tested by the duplex qPCR and an established qPCR assay targeting the 18S $r R N A$ gene of T. equi [30]. Moreover, to further confirm whether the performance of the adopted primers and probe for $B$. caballi in the duplex qPCR would be as robust as that under the original conditions, we tested these samples by the single-target B. caballi $18 \mathrm{~S}$ rRNA qPCR according to the published protocol [27].

\section{Competitive ELISA}

All samples of serum were tested for the presence of antibodies to $B$. caballi and T. equi by cELISA using kits manufactured by VMRD (Pullman, WA, USA). The assays were performed in strict accordance with the manufacturer's protocols, whereby a test sample producing $\geq$ $40 \%$ inhibition was considered positive. Optical density values were obtained using a SpectraMax Plus $384 \mathrm{mi}-$ croplate reader (Molecular Devices, Sunnyvale, CA, USA).

\section{Statistical analysis of the data}

To compare amplification of different sets of standards in the duplex qPCR, standard curves were generated using Prism 6 software (GraphPad Software, La Jolla, CA, USA) by plotting $\mathrm{Cq}$ values against template dilutions or gene copies by non-linear regression (Semilog line). The slope values of these standard curves were equal to those generated by the CFX Manager software (Bio-Rad) for the same qPCR datasets. The slopes of standard curves were then compared using the extra sum-of-squares $F$-test (Prism 6). The data were considered significantly different if the $P$ value was less than 0.05 .

Calculations of Kappa [38], the 95\% CI for a proportion (by the modified Wald method [39]), and positive and negative predictive values of the duplex GPCR were performed using QuickCalcs online resources (Categorical data; GraphPad Software). The 95\% CI values for replicates were calculated using Prism 6. For the Kappa statistic, the software assigns descriptors to the Kappa coefficient $(\kappa)$ value ranges based on the scheme from Altman [38], where $\kappa<2=$ poor agreement; $0.21-0.4=$ fair agreement; $0.41-$ $0.6=$ moderate agreement; $0.61-0.8=$ good agreement; $0.81-0.99=$ very good agreement.

\section{Results}

\section{Optimization of the DNA extraction procedure}

At an early stage of the duplex qPCR development, it was noted that the amplification of DNA preparations extracted strictly according to the spin column-based manufacturer's protocol from duplicate aliquots of a sample of equine blood infected with either of the two piroplasm species produced $\mathrm{Cq}$ values that varied widely between preparations. However, markedly lower and more consistent $\mathrm{Cq}$ values were obtained when ten-fold dilutions of these same DNA preparations were amplified. This indicated the presence of varying amounts of PCR inhibitors in template preparations extracted according to the kit's protocol. To address this problem, we assessed individual effects of several modifications to the DNA extraction procedure on $\mathrm{Cq}$ values in the duplex qPCR. A noticeable improvement in PCR amplification upon addition of BSA to the reaction mixture implies the presence of inhibitory substances in the template preparation [40]. Reduced inhibition in the presence of BSA was pronounced when DNA templates prepared according to the manufacturer's protocol, or to the protocol modified by introducing one additional wash of the spin column containing adsorbed DNA with Buffer AW2, were amplified (Fig. 1). However, even

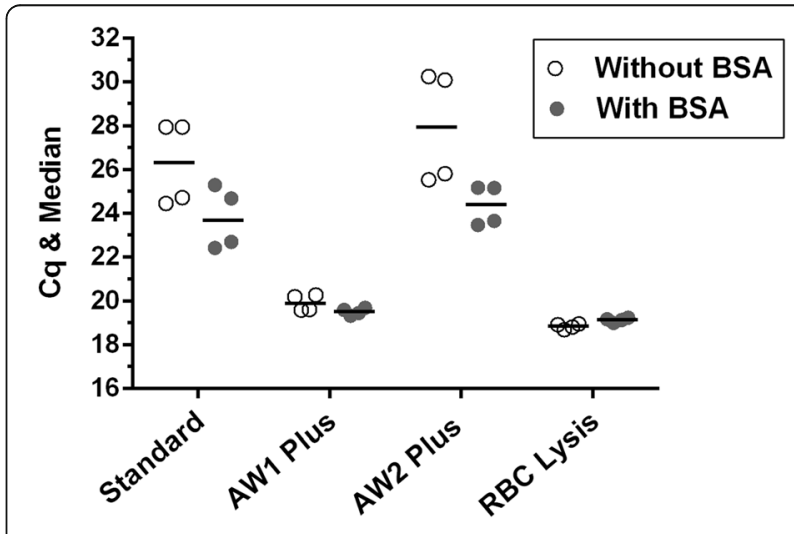

Fig. 1 Optimization of the DNA extraction procedure. Individual $\mathrm{Cq}$ values with median after the duplex qPCR amplification of DNA extracted from $T$. equi-infected equine blood according to the standard protocol provided with the DNA extraction kit or with modifications that involved preliminary lysis of erythrocytes with RBC Lysis Solution or additional wash of the spin column containing adsorbed DNA with either Buffer AW1 (AW1 Plus) or Buffer AW2 (AW2 Plus). These samples were amplified either with or without BSA in the reaction mixture. Graph was produced using Prism 6 
without BSA, modifications entailing the lysis of erythrocytes prior to DNA extraction or an additional wash of the spin column with Buffer AW1 resulted in markedly lower and more consistent $\mathrm{Cq}$ values. Therefore, both these modifications were incorporated into the DNA extraction protocol used in this study (see Methods).

\section{Amplification efficiency and analytical sensitivity of the duplex QPCR}

Acceptable amplification efficiency was repeatedly achieved when serial dilutions of DNA extracted using the optimized protocol from stabilates of equine blood infected with either $T$. equi or B. caballi were prepared and amplified by the duplex qPCR on five separate days. Figure $2(\mathrm{a}, \mathrm{b})$ shows standard curves generated from combined data of these five runs. The $95 \% \mathrm{CI}$ of $\mathrm{E}$ values calculated for separate runs were $93.5-95.6 \%$ for $B$. caballi and $91.8-96.0 \%$ for T. equi.

Analytical sensitivity of the duplex qPCR assay for $T$. equi was assessed by amplification of serial ten-fold dilutions of linearized plasmid DNA containing from one million copies of the ema-1 gene down to one copy. These standards were amplified in either the presence or absence of background DNA from uninfected equine blood. Individual $\mathrm{Cq}$ values of the runs were plotted against copy numbers of the ema-1 gene (Fig. 2c). There was a statistically significant difference $\left(F_{(1,47)}=5.169\right.$,
$P=0.0276)$ between the slope values when calibration curves of standards amplified in the presence or absence of background DNA were compared. The E-value was lower in the presence of background DNA, but it still remained within the acceptance range. Every replicate of the dilution corresponding to 10 copies of the ema-1 gene amplified even in the presence of background DNA with a mean Cq of 36.78 (95\% CI: 36.09-37.46).

To assess the analytical sensitivity for $B$. caballi, the two sets of differently prepared infected blood-derived standards were amplified by the duplex qPCR and individual $\mathrm{Cq}$ values were plotted against template dilutions (Fig. 2d). There was no statistically significant difference between the slopes of these standard curves $\left(F_{(1,44)}=\right.$ $0.4082, P=0.5262)$, and the amplification efficiencies were all within the range of acceptance. All replicates amplified in the $10^{-5}$ dilution with mean Cq of 37.7 (95\% CI: 35.69-39.71), whereas there was no amplification in the subsequent dilution. Therefore, given the starting $0.4 \%$ parasitemia in the blood used for this determination, the analytical sensitivity of the duplex qPCR assay for B. caballi was $4 \times 10^{-6} \%$ infected cells.

\section{Evaluation of diagnostic performance}

For the samples from the 362 presumably EP- negative horses from non-enzootic areas in Canada and USA tested by cELISA and the duplex qPCR, 100\% diagnostic
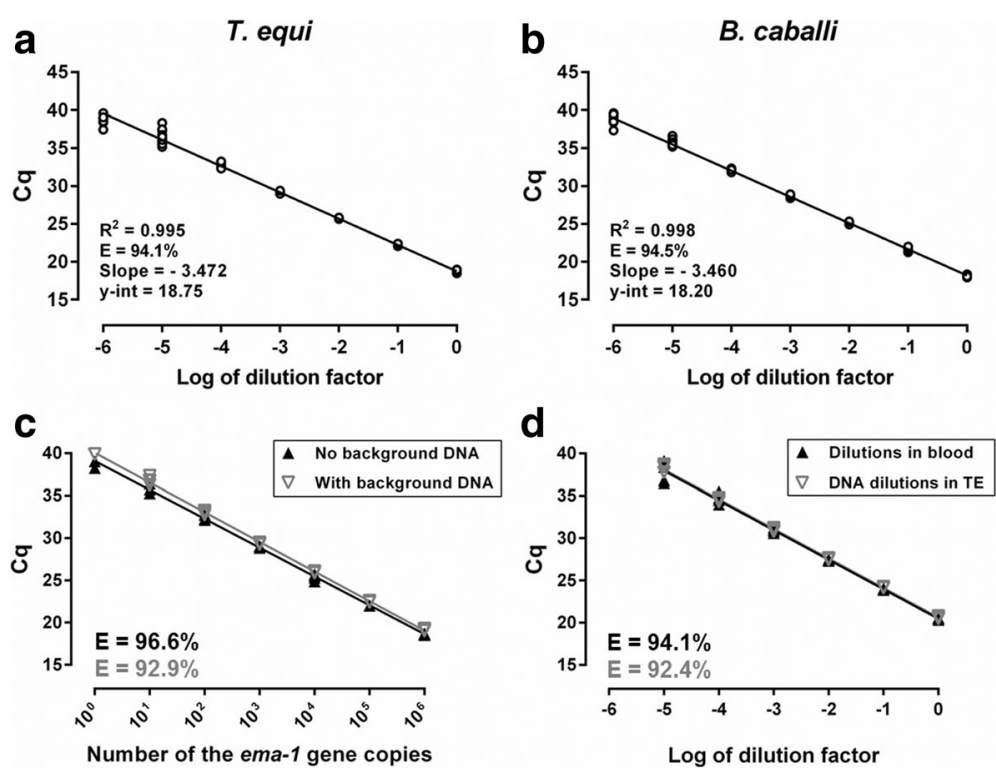

Fig. 2 Standard curves for T. equi (a) and B. caballi (b) generated by plotting pooled Cq values from 5 separate amplifications of standards representing a 6-log dynamic range of starting template quantity (serially diluted DNA extracted from stabilates of infected equine blood) against the log of template dilution factor. Determination of the analytical sensitivity of the duplex qPCR assay for T. equi (c) and B. caballi (d). In $\mathbf{c}$, standard curves were produced by amplification of serial ten-fold dilutions of a linearized plasmid containing the ema- 1 gene of $T$. equi in the presence (gray) or absence (black) of background DNA from uninfected equine blood. Individual Cq values were plotted against the ema-1 gene copy number. In $\mathbf{d}$, Cq values were plotted against the dilution factor of standards represented by DNA extracted from serial ten-fold dilutions of B. caballi-infected equine blood in uninfected equine blood (black) or DNA extracted from the undiluted sample of infected blood serially diluted in TE buffer (gray). Graphs were produced using Prism 6. Abbreviations: $R^{2}$, coefficient of determination; E, amplification efficiency 
specificity was achieved for both assays, with all samples test-negative for both T. equi and B. caballi.

The relative diagnostic sensitivity and specificity of the duplex qPCR were assessed using samples collected from 430 horses of unknown infection status from an enzootic area for EP in Brazil. There was a fairly good agreement between $T$. equi infection prevalence values obtained using the molecular assays (duplex qPCR: 87.9\%; T. equi 18S rRNA qPCR: 90.5\%) and cELISA (87.4\%) (Table 2). In contrast, there was a marked difference between $B$. caballi infection prevalence estimates determined using the qPCR assays (duplex qPCR: 9.3\%; B. caballi $18 \mathrm{~S}$ rRNA qPCR: $7.9 \%)$ and cELISA (58.6\%). By cELISA, 230 of the 430 (53.5\%; 95\% CI: 48.8-58.1\%) horses tested were demonstrated to have antibodies to both piroplasm species. As well, of the 40 horses positive for B. caballi by the duplex qPCR, 38 (95\%; 95\% CI: 82.6-99.5\%) had T. equi (mixed) infections confirmed by both the duplex qPCR and singletarget $18 \mathrm{~S}$ rRNA qPCR for T. equi.

For a more comprehensive comparison of the test results, $2 \times 2$ contingency tables were created and the Kappa statistic was applied. By this analysis, a 'good' agreement was ascribed to the results of the duplex and single-target $18 \mathrm{~S}$ rRNA qPCR tests for T. equi (Fig. 3a), with a $\kappa$ value of 0.747 . Discrepant results were obtained in 21 samples that showed high Cq values that were generally above 36 (mean $\mathrm{Cq} \pm$ standard deviation (SD): $36.83 \pm 1.67$ ). There was a 'very good' agreement between test results of the duplex qPCR and the single-target $18 \mathrm{~S}$ rRNA qPCR for B. caballi $(\kappa=0.882 ;$ Fig. $3 \mathrm{~b})$. Discordant results were detected in only 8 samples with $\mathrm{Cq}$ values above 36 (mean $\mathrm{Cq} \pm$ SD: $38.0 \pm$ 0.97). A 'good' agreement $(\kappa=0.620)$ was also achieved when the results of testing by the duplex qPCR were compared to those of cELISA for T. equi (Fig. 3c). Seventeen of the total $376(4.5 \%)$ seropositive horses were identified as negative and 19 of 54 (35.2\%) seronegative horses were identified as positive by the duplex qPCR. However, for $B$. caballi, the level of agreement between the duplex qPCR and cELISA test results was classified as 'poor' $(\kappa=0.127)$, as only $15.5 \%$ ( 39 of 252 ) of the seropositive horses tested positive by the molecular assay (Fig. 3d). Only one of the 178 antibody-negative animals was identified as positive for this piroplasm species by the duplex qPCR.

Assuming a prevalence of EP in Brazilian horses as determined by cELISA in this study, and given the values of relative diagnostic specificity and sensitivity of the duplex qPCR compared to cELISA as the reference method, positive predictive values of the molecular assay under conditions of high endemicity were nearly $100 \%$ for both $T$. equi and B. caballi infections, whereas negative predictive values for T. equi and B. caballi were 74.2 and $45.5 \%$, respectively.

The frequency distribution of $\mathrm{Cq}$ values obtained from testing of the samples from the 430 Brazilian horses by the molecular assays assessed in this study are shown in Fig. 4. There was a near-symmetrical distribution of Cq values of the duplex qPCR test results for T. equi with a peak at 33 (Fig. 4a). The lowest, median and the highest $\mathrm{Cq}$ values of this dataset were 25.5, 32.7 and 39.4, respectively. Respective Cq values of the single-target $T$. equi $18 \mathrm{~S}$ rRNA qPCR dataset were slightly higher, namely $26.6,35$ and 39.5 . The $\mathrm{Cq}$ value frequency distribution for this molecular assay reached a peak at 35 and was skewed towards higher $\mathrm{Cq}$ values (Fig. 4b). Although there was a very good agreement between test results when $B$. caballi $18 S$ rRNA genespecific primers and probe were used in the duplex or the single-target qPCR, analysis of the frequency distribution of $\mathrm{Cq}$ values suggests a slightly more robust performance of these oligonucleotides under the earlier published conditions (Fig. 4c, d) [27].

\section{Discussion}

In this study, we determined the performance characteristics of a newly developed duplex qPCR assay for simultaneous detection of both causative agents of EP. This assay demonstrated $100 \%$ diagnostic specificity for both T. equi and $B$. caballi when blood samples from 362 seronegative horses and ponies located in non-enzootic areas for EP were tested. This study also showed that in 95.5\% (95\% CI: 92.8-97.3\%) of horses from a highly enzootic area for EP in Brazil with T. equi-positive status, as confirmed by cELISA, parasitemia levels of this organism were at or above the detection limit of the duplex qPCR, supporting a high diagnostic sensitivity of this assay for $T$. equi. This agrees well with high diagnostic sensitivity estimates for molecular assays developed for other Theileria spp. (reviewed in [41]). Since parasitemia levels fluctuate over time, the diagnostic sensitivity of the duplex qPCR assay could be further improved by serial testing of initially cELISA-positive/qPCR-negative animals. Of the 54

Table 2 Test results of the molecular assays and cELISA on samples from 430 Brazilian horses

\begin{tabular}{|c|c|c|c|c|c|c|}
\hline \multirow[t]{2}{*}{ Positive } & \multicolumn{3}{|l|}{ Theileria equi } & \multicolumn{3}{|l|}{ Babesia caballi } \\
\hline & Duplex qPCR & $18 \mathrm{~S}$ rRNA qPCR ${ }^{a}$ & EMA-1 CELISA & Duplex qPCR & $18 \mathrm{~S}$ rRNA qPCR & RAP-1 cELISA \\
\hline$n$ & 378 & 389 & 376 & 40 & 34 & 252 \\
\hline$\%$ & 87.9 & 90.5 & 87.4 & 9.3 & 7.9 & 58.6 \\
\hline $95 \% \mathrm{Cl}$ & $84.5-90.7$ & $87.3-92.3$ & $84.0-90.2$ & $6.9-12.4$ & $5.7-10.9$ & $53.9-63.2$ \\
\hline
\end{tabular}

${ }^{\text {aKim et al. [30] }}$

${ }^{\mathrm{b}}$ Bhoora et al. [27] 

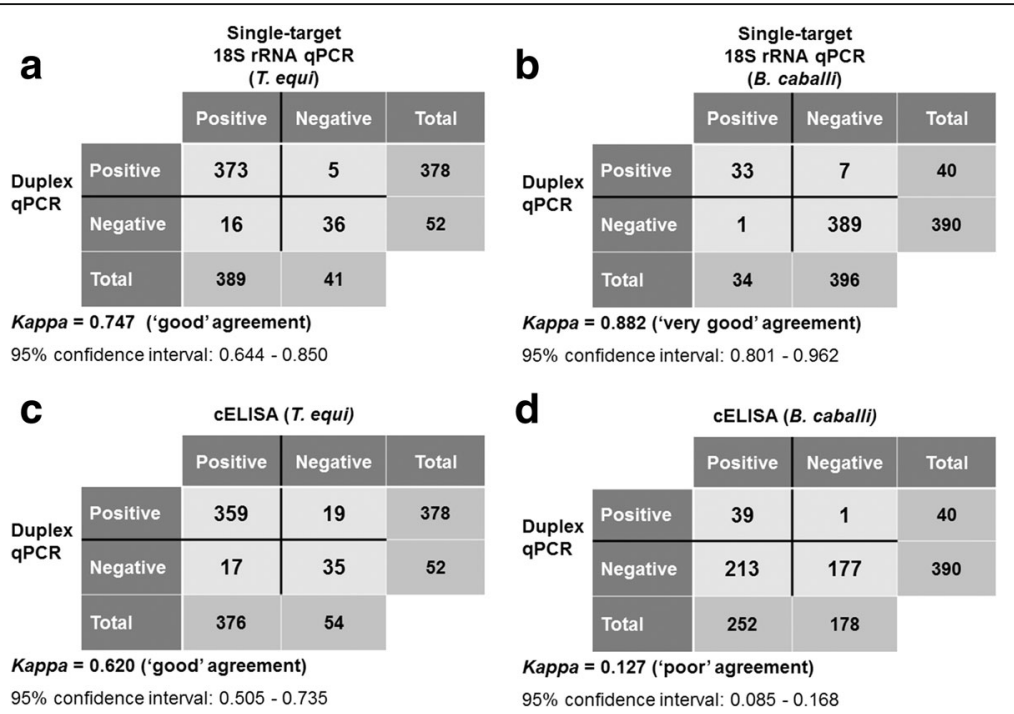

Fig. 3 Level of agreement between test results of the duplex qPCR and those of the single-target 18S rRNA qPCR for T. equi (a), single-target 18S rRNA qPCR for B. caballi (b), cELISA for T. equi (c) and cELISA for B. caballi (d) performed on samples from 430 Brazilian horses

Brazilian horses with no detectable antibodies to T. equi on cELISA, 19 (35.2\%) tested positive for this piroplasm species in the duplex qPCR (Fig. 3c). This is consistent with other recently published data demonstrating significantly higher sensitivity of a PCR assay compared to cELISA in detecting early $T$. equi infections [12].

The ema-1 gene of $T$. equi targeted by the duplex qPCR was originally described as a single-copy gene
[42]. However, recently published genome sequence data for this piroplasm species revealed that ema-1 belongs to a family of at least nine other genes [43]. Since these genes share comparatively low-level nucleotide identities with one another, it is likely that the ema-1 gene-specific primers and hydrolysis probe target a single genomic locus. This would make these oligonucleotides especially suitable for quantitative assessment of $T$. equi loads by
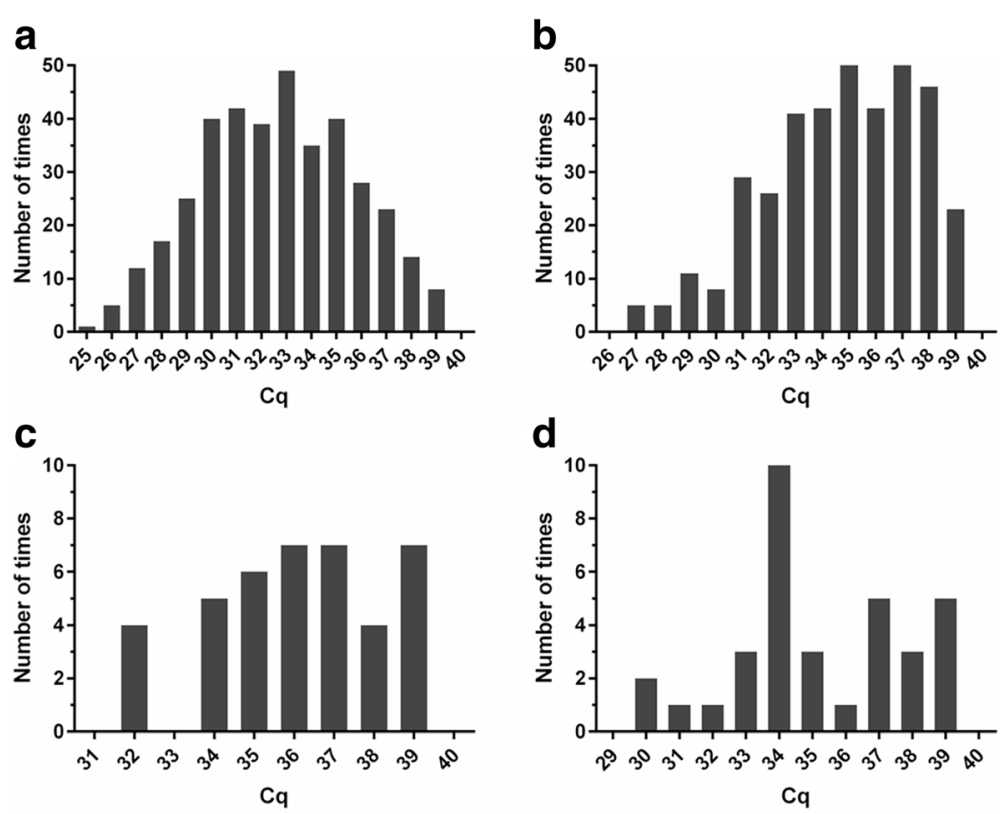

Fig. 4 Frequency distribution of Cq values obtained by testing blood samples from 430 Brazilian horses for T. equi by the duplex qPCR (a) and the single-target $T$. equi 185 rRNA gene-specific qPCR (b), as well as for B. caballi by the duplex qPCR (c) and the single-target $B$. caballi 185 rRNA gene-specific qPCR $(\mathbf{d})$. For samples with amplification plots produced in both duplicates, mean of these Cq values was used for the analysis, whereas when only one of the duplicates amplified, that single Cq value was used unaltered. Graphs were generated using Prism 6 
qPCR. The duplex qPCR assay reliably detected at least 10 copies of ema-1 in the presence of background DNA from equine blood. This would roughly translate to one organism per microliter of blood, which is similar to analytical sensitivity estimates for other qPCR assays recognized as sensitive for the detection of equine or bovine piroplasm species $[28,30,44]$.

Performance of the duplex qPCR assay was compared in this study to that of a previously developed singletarget $18 \mathrm{~S}$ rRNA qPCR for T. equi [30] using samples from Brazilian horses. The latter assay has been applied in numerous studies performed by various research groups, which substantiated its reliable performance [27, 45-47]. There was a good agreement in our study between the duplex qPCR and the $18 \mathrm{~S}$ rRNA qPCR for $T$. equi (Table 2, Fig. 3a). The prevalence values obtained using these molecular assays (87.9 and $90.5 \%$, respectively) agree well with the $T$. equi seroprevalence of $87.4 \%$ revealed in this horse population by cELISA. A higher proportion of horses identified as positive by the $18 \mathrm{~S}$ rRNA qPCR may be due to a slightly higher analytical sensitivity of this assay compared to that of the duplex qPCR, as $T$. equi has two rRNA operons [43]. There might also be yet uncharacterized rare variants of the ema-1 gene bearing polymorphisms in the hybridization sites for primers and/or probe developed in this study that interfere with assay performance. However, this might also apply to $T$. equi-specific qPCR methods targeting the $18 S$ rRNA gene, as comparatively high levels of sequence heterogeneity in this gene were revealed among different strains of $T$. equi [48-50].

By contrast, the level of concordance between the cELISA and duplex qPCR results from testing of Brazilian horses for B. caballi was poor (Table 2, Fig. 3d). However, this is not attributable to a less efficient performance of $B$. caballi $18 S$ rRNA gene-specific primers and hydrolysis probe developed by Bhoora et al. [27] under the duplex qPCR conditions. The detection limit of the single-target $18 \mathrm{~S}$ rRNA qPCR assay, defined as the level of B. caballi parasitemia at which $95 \%$ of positive samples were detected, has been determined to be $1.14 \times 10^{-4} \%$ infected cells, corresponding to a $\mathrm{Cq}$ of 35.82 [27]. The performance of these oligonucleotides in the duplex qPCR was similarly robust, as evidenced by the following: (i) $\mathrm{Cq}$ values of $\leq 35.5$ were obtained in all replicates of the dilution corresponding to $4 \times 10^{-5} \%$ infected cells, and (ii) the results of testing field samples from a representative number of horses from Brazil, an enzootic area for EP, by both the duplex qPCR and the single-target $18 \mathrm{~S}$ rRNA qPCR for $B$. caballi were in a very good agreement (Fig. 3b). A markedly higher level of agreement between this 18S rRNA qPCR assay and IFAT has been reported for testing of field samples from South African horses [27]. Of the 41 horses tested in that study, $29(70.7 \%)$ had detectable antibodies to $B$. caballi and only three out of these seropositive horses tested negative by the $18 \mathrm{~S}$ rRNA qPCR. In our study, only 34 out of 252 (13.5\%) Brazilian horses with antibodies to $B$. caballi detectable in cELISA were identified as positive by the single-target $18 \mathrm{~S}$ rRNA qPCR. The reason for such a noticeable difference in the proportion of seropositive horses identified as positive by this molecular assay for the two populations of horses tested remains unknown.

A significantly higher seroprevalence of $B$. caballi infection compared to that demonstrated by molecular assays has been reported in several other epidemiological studies [21, 29, 51-54]. In 487 horses from four states in Brazil, including the same region assessed in the current study, and tested for both causative agents of EP by IFAT and a duplex qPCR assay targeting the ema-1 gene of $T$. equi and the $b c 48$ gene of $B$. caballi, high seroprevalence values of 91 and $83 \%$ were obtained for $T$. equi and B. caballi, respectively [29]. However, in both that and our current study, the number of horses that tested positive for B. caballi by molecular assay was only approximately one-sixth that of the animals with detectable antibodies to this piroplasm species. Significantly higher seroprevalences compared to prevalence estimates obtained using nPCR have also been reported for $B$. bovis and B. bigemina infections in water buffaloes from enzootic areas in Mexico and Egypt $[55,56]$.

In another study, a representative number of horses sampled in south-western Mongolia were tested for both T. equi and B. caballi using IFAT and a conventional duplex PCR [21]. By applying logistic regression models to the data, an age-dependent increase in prevalence as determined by PCR was shown for $T$. equi but a decrease was demonstrated for B. caballi. However, there was an age-dependent increase in the proportion of IFATpositive horses for both piroplasm species. These data seem to support the contention that, unlike lifelong chronic infections caused by $T$. equi, horses might eventually clear infections with $B$. caballi without babesiacidal treatment. However, persistence of detectable levels of antibodies to $B$. caballi suggests the presence of viable parasites in the host, as supported by previous work that demonstrated that detectable antibodies specific to this piroplasm species wane within a few months after parasite clearance [34].

Interestingly, compared to the $B$. caballi prevalence estimates for Brazilian horses obtained in our study, there was a higher level of agreement between the numbers of seropositive and positive PCR results for Mongolian horses tested for $B$ caballi [21], in spite of the conventional PCR that was used in that study, which generally has a lower sensitivity than qPCR. This may be attributable to several factors including differing dynamics of 
exposure to $B$. caballi for horses in these enzootic areas. More frequent exposure of horses to $B$. caballi-infected ticks is more likely to occur in Brazil where this pathogen is vectored by Dermacentor nitens, a one-host tick species that produces about three generations annually [57]. By contrast, immature stages of D. nuttalli, a known vector of this piroplasm species in Mongolia, generally feed on small mammals and infestations of horses with this tick species follow a seasonal pattern [58]. It remains to be determined whether a more frequent exposure to $B$. caballi confers better control over antigenically diverse parasite variants by the host's immune system, resulting in reduced levels of parasitemia, analogous to the clinical course and pathogenesis of Plasmodium spp. infection in humans $[59,60]$.

Babesia species employ sequential modification of parasite-derived antigen expressed on the surface of parasitized erythrocytes as a strategy for resisting host immunity [61]. In some species of Babesia this surfaceexposed antigen is also responsible for adhesion of infected red blood cells to vascular endothelium leading to sequestration of parasitized cells in the microvasculature of different host tissues. It is not known whether the reduction of parasitemia levels of $B$. caballi in persistently infected horses is influenced by this phenomenon.

The level of agreement between $T$. equi infection prevalence estimates for Brazilian horses determined by serology and qPCR in the study published by Heim et al. [29] was lower than that in our study. The higher diagnostic sensitivity of our duplex qPCR assay for $T$. equi may be attributed to a wider range of allele specificity of the ema-1-specific oligonucleotides developed in this study, and/or to the modifications that we introduced in our assay's protocol to eliminate adverse effects of PCR inhibitors from blood. This study demonstrated that PCR inhibitors present in DNA extracted from equine blood using a widely-employed commercial protocol at levels that were not sufficient for complete abrogation of the amplification still caused a significant increase in Cq values (Fig. 1), thus affecting the assay's sensitivity. This would also affect the accuracy of quantification by qPCR if serial dilutions of the standard used (e.g. purified plasmid DNA fragment or PCR product) were not subject to the same matrix effect. However, the problem can be mitigated by utilizing the modified DNA extraction procedure used here, or any other DNA extraction method that similarly entails a more thorough removal of inhibitory haem components from such DNA preparations.

\section{Conclusions}

This study provides validation data for a new duplex qPCR assay for the diagnosis of EP that utilizes newly developed primers and TaqMan MGB probe for the ema-1 gene of $T$. equi, and B. caballi $18 S$ rRNA gene-specific primers and
MGB probe adopted from an earlier study [27]. The advantage of this qPCR is that it is a multiplex assay with performance characteristics similar to those of wellestablished single-target qPCR assays recognized as sensitive for the detection of EP. The analytical sensitivity of this assay was confirmed to be high for both causative agents of EP, which should enable the detection of single or mixed infections with very low levels of parasitemia. The assay demonstrated high diagnostic specificity for both piroplasm species, as there were no false-positive reactions in testing of samples from a representative number of seronegative horses from non-enzootic areas for EP. Relative diagnostic sensitivity was similarly high $(95.5 \%)$ for $T$. equi when a subset of Brazilian horses with antibodies to this piroplasm species detected by cELISA $(n=376)$ was analysed. However, only $15.5 \%$ of the 252 Brazilian horses with detectable antibodies to $B$. caballi had parasitemia levels at or above the detection limit of this molecular assay. Capillary blood sampling may need to be considered as a potential approach for improving the diagnostic sensitivity of molecular assays for B. caballi. Given savings in turnaround time and reagent costs provided by multiplexing in comparison to a singletarget assay format, the duplex qPCR assay developed in this study is suitable for epidemiological surveys. However, the results presented here further demonstrate that prevalence studies performed using only molecular methods may significantly underestimate the prevalence of exposure to $B$. caballi. The data presented here support the suitability of the ema-1-specific oligonucleotides developed in this study for confirmatory testing of non-negative serological test results for $T$. equi by qPCR. However, for B. caballi, only positive molecular test results can be interpreted with confidence when determining the infection status of individual animals for disease control and regulatory purposes.

\section{Abbreviations \\ CFAP: Center for Food-borne and Animal Parasitology; EP: equine piroplasmosis; PCR: polymerase chain reaction; qPCR: quantitative real-time PCR; nPCR: 'nested' PCR; cELISA: competitive enzyme-linked immunosorbent assay; IFAT: indirect immunofluorescent antibody test; CFT: complement fixation test; EMA-1: equi merozoite antigen 1; RAP-1: rhoptry-associated protein 1; bc48: gene encoding a 48-kilodalton merozoite rhoptry protein of B. caballi; EDTA: ethylene diamine tetra-acetic acid; BSA: bovine serum albumin; MGB: minor groove binder; NFQ: non-fluorescent quencher; Cl: confidence interval; Cq: quantification cycle}

\section{Acknowledgements}

The authors would like to thank Yunxiu Dai, Robyn Ostrander and Jenna Oakley (CFAP, CFIA) for excellent technical support. We are thankful to Dr Randal Capsel (NVSL/USDA) for providing cryopreserved stabilates and fresh samples of blood from horses infected with either T. equi or B. caballi, and to Dr Stephen Manning (WCVM, University of Saskatchewan) for fresh EP-negative horse blood. We thank Dr Daniel Howe and other staff of the Gluck Equine Research Center (University of Kentucky) for providing archived samples from EP-negative U.S. horses. The authors wish to thank the entire working group of the Haemoparasites and Vectors Laboratory at the Federal Rural University of Rio de Janeiro, particularly Marcus S. Pires and Gabriela L. Vitari, for coordinating the collection of equine blood samples. We also thank Dr Sarah Parker (WCVM, University of Saskatchewan) for consultations concerning the determination of sample size and Dr Caroline Frey (CFAP, CFIA) for critically reviewing the manuscript. 


\section{Funding}

This work was funded by the Canadian Food Inspection Agency. The sample collection in Brazil was supported by a grant from the Coordination for the Improvement of Higher Education Personnel (CAPES) Foundation, Ministry of Education of Brazil.

\section{Availability of data and materials}

All relevant data supporting the conclusions of this study are included within the article. The raw data are available from the corresponding author upon reasonable request.

\section{Authors' contributions}

VAL and AAG designed the study. MP, WBS, AAG and CLM coordinated sample collection. VAL carried out the study and analyzed/interpreted the data. VAL and WBS drafted the manuscript. All authors contributed to the content. All authors read and approved the final manuscript.

\section{Ethics approval and consent to participate}

The collection of blood samples from horses in the state of Rio de Janeiro, Brazil was approved by the Ethics Committee on Animal Research of the Federal Rural University of Rio de Janeiro (COMEP / UFRRJ), under process number 23083.001257/2012-53 (protocol number 201/2012). Collections of blood from horses located in Canada and the United States were approved by the University of Saskatchewan Committee on Animal Care and Supply and by the NVSL/Center for Veterinary Biologics Institutional Animal Care and Use Committee, respectively.

\section{Consent for publication}

Not applicable.

\section{Competing interests}

The authors declare that they have no competing interests.

\section{Publisher's Note}

Springer Nature remains neutral with regard to jurisdictional claims in published maps and institutional affiliations.

\section{Author details}

${ }^{1}$ Centre for Food-borne and Animal Parasitology, Canadian Food Inspection Agency, Saskatoon, Saskatchewan, Canada. ${ }^{2}$ Department of Animal Parasitology, Veterinary Institute, Federal Rural University of Rio de Janeiro, Seropedica, Rio de Janeiro, Brazil.

\section{Received: 2 October 2017 Accepted: 26 February 2018}

Published online: 02 March 2018

\section{References}

1. Mehlhorn H, Schein E. Redescription of Babesia equi Laveran, 1901 as Theileria equi Mehlhorn, Schein 1998. Parasitol Res. 1998;84:467-75.

2. Nutall GHF, Strickland C. Die parasiten der pferdepiroplasmose resp. der "biliary fever". Zentralbl Bakt Mikrobiol. 1910;1:524-5.

3. De Waal DT. Equine piroplasmosis: a review. Br Vet J. 1992;148:6-14.

4. Thompson $\mathrm{PH}$. Ticks as vectors of equine piroplasmosis. J Am Vet Med Assoc. 1969;155:454-7.

5. Phipps LP, Otter A. Transplacental transmission of Theileria equi in two foals born and reared in the United Kingdom. Vet Rec. 2004;154:406-8.

6. Scoles GA, Ueti MW. Vector ecology of equine piroplasmosis. Annu Rev Entomol. 2015;60:561-80.

7. Scoles GA, Ueti MW. Amblyomma cajennense is an intrastadial biologica vector of Theileria equi. Parasit Vectors. 2013;6:306.

8. Scoles GA, Hutcheson HJ, Schlater JL, Hennager SG, Pelzel AM, Knowles DP. Equine piroplasmosis associated with Amblyomma cajennense ticks, Texas, USA. Emerg Infect Dis. 2011;17:1903-5.

9. Friedhoff KT, Tenter AM, Muller I. Haemoparasites of equines: impact on international trade of horses. Rev Sci Tech. 1990;9:1187-94.

10. Bashiruddin JB, Camma C, Rebelo E. Molecular detection of Babesia equi and Babesia caballi in horse blood by PCR amplification of part of the 165 rRNA gene. Vet Parasitol. 1999;84:75-83.

11. Nicolaiewsky TB, Richter MF, Lunge VR, Cunha CW, Delagostin O, Ikuta N, et al. Detection of Babesia equi (Laveran, 1901) by nested polymerase chain reaction. Vet Parasitol. 2001;101:9-21.
12. Grause JF, Ueti MW, Nelson JT, Knowles DP, Kappmeyer LS, Bunn TO. Efficacy of imidocarb dipropionate in eliminating Theileria equi from experimentally infected horses. Vet J. 2013;196:541-6.

13. Knowles DP, Kappmeyer LS, Stiller D, Hennager SG, Perryman LE. Antibody to a recombinant merozoite protein epitope identifies horses infected with Babesia equi. J Clin Microbiol. 1992;30:3122-6.

14. Wise LN, Kappmeyer LS, Mealey RH, Knowles DP. Review of equine piroplasmosis. J Vet Intern Med. 2013;27:1334-46.

15. Knowles DP, Perryman LE, Kappmeyer LS, Hennager SG. Detection of equine antibody to Babesia equi merozoite proteins by a monoclonal antibody-based competitive inhibition enzyme-linked immunosorbent assay. J Clin Microbiol. 1991;29:2056-8.

16. Rhalem A, Sahibi H, Lasri S, Johnson WC, Kappmeyer LS, Hamidouch A, et al. Validation of a competitive enzyme-linked immunosorbent assay for diagnosing Babesia equi infections of Moroccan origin and its use in determining the seroprevalence of B. equi in Morocco. J Vet Diagn Invest. 2001;13:249-51.

17. Kappmeyer LS, Perryman LE, Hines SA, Baszler TV, Katz JB, Hennager SG, et al. Detection of equine antibodies to Babesia caballi by recombinant $B$. caballi rhoptry-associated protein 1 in a competitive-inhibition enzymelinked immunosorbent assay. J Clin Microbiol. 1999;37:2285-90.

18. Bhoora R, Quan M, Zweygarth E, Guthrie AJ, Prinsloo SA, Collins NE. Sequence heterogeneity in the gene encoding the rhoptry-associated protein-1 (RAP-1) of Babesia caballi isolates from South Africa. Vet Parasitol. 2010;169:279-88.

19. Rapoport A, Aharonson-Raz K, Berlin D, Tal S, Gottlieb Y, Klement E, et al. Molecular characterization of the Babesia caballi rap-1 gene and epidemiological survey in horses in Israel. Infect Genet Evol. 2014;23:115-20.

20. Awinda PO, Mealey RH, Williams LB, Conrad PA, Packham AE, Reif KE, et al. Serum antibodies from a subset of horses positive for Babesia caballi by competitive enzyme-linked immunosorbent assay demonstrate a protein recognition pattern that is not consistent with infection. Clin Vaccine Immunol. 2013;20:1752-7.

21. Ruegg SR, Torgerson P, Deplazes P, Mathis A. Age-dependent dynamics of Theileria equi and Babesia caballi infections in southwest Mongolia based on IFAT and/or PCR prevalence data from domestic horses and ticks. Parasitology. 2007;134:939-47.

22. Alhassan A, Pumidonming W, Okamura M, Hirata $H$, Battsetseg B, Fujisaki $K$ et al. Development of a single-round and multiplex PCR method for the simultaneous detection of Babesia caballi and Babesia equi in horse blood. Vet Parasitol. 2005;129:43-9.

23. Battsetseg B, Lucero S, Xuan X, Claveria FG, Inoue N, Alhassan A, et al. Detection of natural infection of Boophilus microplus with Babesia equi and Babesia caballi in Brazilian horses using nested polymerase chain reaction. Vet Parasitol. 2002:107:351-7.

24. Schwint ON, Knowles DP, Ueti MW, Kappmeyer LS, Scoles GA. Transmission of Babesia caballi by Dermacentor nitens (Acari: Ixodidae) is restricted to one generation in the absence of alimentary reinfection on a susceptible equine host. J Med Entomol. 2008:45:1152-5.

25. Nagore D, Garcia-Sanmartin J, Garcia-Perez AL, Juste RA, Hurtado A. Detection and identification of equine Theileria and Babesia species by reverse line blotting: epidemiological survey and phylogenetic analysis. Vet Parasitol. 2004:123:41-54

26. Alhassan A, Thekisoe OM, Yokoyama N, Inoue N, Motloang MY, Mbati PA, et al. Development of loop-mediated isothermal amplification (LAMP) method for diagnosis of equine piroplasmosis. Vet Parasitol. 2007;143:155-60.

27. Bhoora R, Quan M, Franssen L, Butler CM, van der Kolk JH, Guthrie AJ, et al. Development and evaluation of real-time PCR assays for the quantitative detection of Babesia caballi and Theileria equi infections in horses from South Africa. Vet Parasitol. 2010;168:201-11.

28. Bhoora R, Quan M, Matjila PT, Zweygarth E, Guthrie AJ, Collins NE. Sequence heterogeneity in the equi merozoite antigen gene (ema-1) of Theileria equi and development of an ema-1-specific TaqMan MGB assay for the detection of T. equi. Vet Parasitol. 2010;172:33-45.

29. Heim A, Passos LM, Ribeiro MF, Costa-Junior LM, Bastos CV, Cabral DD, et al. Detection and molecular characterization of Babesia caballi and Theileria equi isolates from endemic areas of Brazil. Parasitol Res. 2007;102:63-8.

30. Kim CM, Blanco LB, Alhassan A, Iseki H, Yokoyama N, Xuan X, et al. Diagnostic real-time PCR assay for the quantitative detection of Theileria equi from equine blood samples. Vet Parasitol. 2008:151:158-63.

31. Espy MJ, Uhl JR, Sloan LM, Buckwalter SP, Jones MF, Vetter EA, et al. Real-time $P C R$ in clinical microbiology: applications for routine laboratory testing. Clin Microbiol Rev. 2006;19:165-256. 
32. Ueti MW, Palmer GH, Kappmeyer LS, Scoles GA, Knowles DP. Expression of equi merozoite antigen 2 during development of Babesia equi in the midgut and salivary gland of the vector tick Boophilus microplus. J Clin Microbiol. 2003:41:5803-9.

33. Ueti MW, Palmer GH, Kappmeyer LS, Statdfield M, Scoles GA, Knowles DP. Ability of the vector tick Boophilus microplus to acquire and transmit Babesia equi following feeding on chronically infected horses with low-level parasitemia. J Clin Microbiol. 2005:43:3755-9.

34. Schwint ON, Ueti MW, Palmer GH, Kappmeyer LS, Hines MT, Cordes RT, et al. Imidocarb dipropionate clears persistent Babesia caballi infection with elimination of transmission potential. Antimicrob Agents Chemother. 2009;53:4327-32.

35. Ueti MW, Mealey RH, Kappmeyer LS, White SN, Kumpula-McWhirter N, Pelzel $\mathrm{AM}$, et al. Re-emergence of the apicomplexan Theileria equi in the United States: elimination of persistent infection and transmission risk. PloS One. 2012;7:e44713.

36. Hall TA. BioEdit: a user-friendly biological sequence alignment editor and analysis program for Windows 95/98/NT. Nucl Acids Symp Ser. 1999;41:95-8.

37. Applied Biosystems. Creating standard curves with genomic DNA or plasmid DNA templates for use in quantitative PCR. 2003. http://www6.appliedbiosystems. com/support/tutorials/pdf/quant_pcr.pdf. Accessed 2 Aug 2012.

38. Altman DG. Practical statistics for medical research. 1st ed. London: Chapman and Hall; 1991.

39. Agresti A, Coull BA. Approximate is better than "exact" for interval estimation of binomial proportions. Am Stat. 1998;52:119-26.

40. Kreader CA. Relief of amplification inhibition in PCR with bovine serum albumin or T4 gene 32 protein. Appl Environ Microbiol. 1996;62:1102-6.

41. Mans BJ, Pienaar R, Latif AA. A review of Theileria diagnostics and epidemiology. Int J Parasitol Parasites Wildl. 2015;4:104-18.

42. Kappmeyer LS, Perryman LE, Knowles DP Jr. A Babesia equi gene encodes a surface protein with homology to Theileria species. Mol Biochem Parasitol. 1993;62:121-4

43. Kappmeyer LS, Thiagarajan M, Herndon DR, Ramsay JD, Caler E, Djikeng A et al. Comparative genomic analysis and phylogenetic position of Theileria equi. BMC Genomics. 2012;13:603.

44. Criado-Fornelio A, Buling A, Asenzo G, Benitez D, Florin-Christensen M, Gonzalez-Oliva A, et al. Development of fluorogenic probe-based PCR assays for the detection and quantification of bovine piroplasmids. Vet Parasitol. 2009;162:200-6.

45. Alanazi AD, Said AE, Morin-Adeline V, Alyousif MS, Slapeta J. Quantitative PCR detection of Theileria equi using laboratory workflows to detect asymptomatic persistently infected horses. Vet Parasitol. 2014;206:138-45.

46. Pitel PH, Pronost S, Scrive T, Leon A, Richard E, Fortier G. Molecular detection of Theileria equi and Babesia caballi in the bone marrow of asymptomatic horses. Vet Parasitol. 2010;170:182-4.

47. Peckle M, Pires MS, Dos Santos TM, Roier EC, da Silva CB, Vilela JA, et al. Molecular epidemiology of Theileria equi in horses and their association with possible tick vectors in the state of Rio de Janeiro, Brazil. Parasitol Res. 2013;112:2017-25

48. Bhoora R, Franssen L, Oosthuizen MC, Guthrie AJ, Zweygarth E, Penzhorn BL, et al. Sequence heterogeneity in the 185 rRNA gene within Theileria equi and Babesia caballi from horses in South Africa. Vet Parasitol. 2009;159:112-20.

49. Liu Q, Meli ML, Zhang Y, Meili T, Stirn M, Riond B, et al. Sequence heterogeneity in the $18 \mathrm{~S}$ rRNA gene in Theileria equi from horses presented in Switzerland. Vet Parasitol. 2016;221:24-9.

50. Qablan MA, Obornik M, Petrzelkova KJ, Sloboda M, Shudiefat MF, Horin P et al. Infections by Babesia caballi and Theileria equi in Jordanian equids: epidemiology and genetic diversity. Parasitology. 2013;140:1096-103.

51. Butler CM, Sloet van Oldruitenborgh-Oosterbaan MM, Stout TA, van der Kolk JH, Wollenberg L, Nielen $M$, et al. Prevalence of the causative agents of equine piroplasmosis in the South West of the Netherlands and the identification of two autochthonous clinical Theileria equi infections. Vet J. 2012;193:381-5.

52. Machado RZ, Toledo CZ, Teixeira MC, Andre MR, Freschi CR, Sampaio PH. Molecular and serological detection of Theileria equi and Babesia caballi in donkeys (Equus asinus) in Brazil. Vet Parasitol. 2012;186:461-5.

53. Posada-Guzman MF, Dolz G, Romero-Zuniga JJ, Jimenez-Rocha AE. Detection of Babesia caballi and Theileria equi in blood from equines from four indigenous communities in Costa Rica. Vet Med Int. 2015;2015:236278.

54. Rosales R, Rangel-Rivas A, Escalona A, Jordan LS, Gonzatti MI, Aso PM, et al. Detection of Theileria equi and Babesia caballi infections in Venezuelan horses using Competitive-Inhibition ELISA and PCR. Vet Parasitol. 2013;196:37-43.
55. Mahmoud MS, Kandil OM, Nasr SM, Hendawy SH, Habeeb SM, Mabrouk DM et al. Serological and molecular diagnostic surveys combined with examining hematological profiles suggests increased levels of infection and hematological response of cattle to babesiosis infections compared to native buffaloes in Egypt. Parasit Vectors. 2015;8:319.

56. Romero-Salas D, Mira A, Mosqueda J, Garcia-Vazquez Z, Hidalgo-Ruiz M, Vela NA, et al. Molecular and serological detection of Babesia bovis- and Babesia bigemina-infection in bovines and water buffaloes raised jointly in an endemic field. Vet Parasitol. 2016;217:101-7.

57. Rodrigues VD, Garcia MV, Cruz BC, Maciel WG, Zimmermann NP, Koller WW, et al. Life cycle and parasitic competence of Dermacentor nitens Neumann, 1897 (Acari: Ixodidae) on different animal species. Ticks Tick Borne Dis. 2017;8:379-84.

58. Arthur DR. Ticks: a monograph of the Ixodoidea. Cambridge: Cambridge University Press; 1960.

59. Krause PJ, Daily J, Telford SR, Vannier E, Lantos P, Spielman A. Shared features in the pathobiology of babesiosis and malaria. Trends Parasitol. 2007;23:605-10.

60. Doolan DL, Dobano C, Baird JK. Acquired immunity to malaria. Clin Microbiol Rev. 2009;22:13-36.

61. Jackson AP, Otto TD, Darby A, Ramaprasad A, Xia D, Echaide IE, et al. The evolutionary dynamics of variant antigen genes in Babesia reveal a history of genomic innovation underlying host-parasite interaction. Nucleic Acids Res. 2014;42:7113-31.

\section{Submit your next manuscript to BioMed Central and we will help you at every step:}

- We accept pre-submission inquiries

- Our selector tool helps you to find the most relevant journal

- We provide round the clock customer support

- Convenient online submission

- Thorough peer review

- Inclusion in PubMed and all major indexing services

- Maximum visibility for your research

Submit your manuscript at www.biomedcentral.com/submit

) BioMed Central 